\title{
Serum Galactose-Deficient IgA1 Level Is Not Associated with Proteinuria in Children with IgA Nephropathy
}

\author{
M. Colleen Hastings, ${ }^{1,2,3}$ Sabahat Afshan, ${ }^{1,2}$ John T. Sanders, ${ }^{4}$ \\ Oulimata Kane, ${ }^{1,2}$ T. Matthew Eison, ${ }^{1,2}$ Keith K. Lau, ${ }^{5}$ Zina Moldoveanu, ${ }^{6}$ Bruce A. Julian, ${ }^{6,7}$ \\ Jan Novak, ${ }^{6}$ and Robert J. Wyatt ${ }^{1,2}$ \\ ${ }^{1}$ Children's Foundation Research Institute, Le Bonheur Children's Hospital, 50 North Dunlap, Memphis, TN 38103-2893, USA \\ ${ }^{2}$ Department of Pediatrics, University of Tennessee Health Science Center, 50 North Dunlap, Memphis, TN 38103, USA \\ ${ }^{3}$ Department of Medicine, University of Tennessee Health Science Center, 956 Court Avenue, Memphis, TN 38163, USA \\ ${ }^{4}$ Sanford Children's Hospital Sioux Falls, 1305 W 18th Street, Sioux Falls, SD 57117-5039, USA \\ ${ }^{5}$ Department of Pediatrics, McMaster University, 1280 Main Street, West Hamilton, ON, Canada L8S 4K1 \\ ${ }^{6}$ Department of Microbiology, University of Alabama at Birmingham, 845 19th Street South, Birmingham, AL 35294, USA \\ ${ }^{7}$ Division of Nephrology, Department of Medicine, University of Alabama at Birmingham, 1530 Third Avenue South, Birmingham, \\ AL 35294, USA
}

Correspondence should be addressed to M. Colleen Hastings, mhasting@uthsc.edu

Received 8 February 2012; Accepted 13 April 2012

Academic Editor: Omran Bakoush

Copyright (๑) 2012 M. Colleen Hastings et al. This is an open access article distributed under the Creative Commons Attribution License, which permits unrestricted use, distribution, and reproduction in any medium, provided the original work is properly cited.

\begin{abstract}
Introduction. Percentage of galactose-deficient $\operatorname{IgA} 1$ (Gd-IgA1) relative to total IgA in serum was recently reported to correlate with proteinuria at time of sampling and during follow-up for pediatric and adult patients with IgA nephropathy. We sought to determine whether this association exists in another cohort of pediatric patients with IgA nephropathy. Methods. Subjects were younger than 18 years at entry. Blood samples were collected on one or more occasions for determination of serum total IgA and Gd-IgA1. Gd-IgA1 was expressed as serum level and percent of total IgA. Urinary protein/creatinine ratio was calculated for random specimens. Spearman's correlation coefficients assessed the relationship between study variables. Results. The cohort had 29 Caucasians and 11 African-Americans with a male: female ratio of $1.9: 1$. Mean age at diagnosis was $11.7 \pm 3.7$ years. No statistically significant correlation was identified between serum total IgA, Gd-IgA1, or percent Gd-IgA1 versus urinary protein/creatinine ratio determined contemporaneously with biopsy or between average serum Gd-IgAl or average percent GdIgAl and time-average urinary protein/creatinine ratio. Conclusion. The magnitude of proteinuria in this cohort of pediatric patients with IgA nephropathy was influenced by factors other than Gd-IgA1 level, consistent with the proposed multi-hit pathogenetic pathways for this renal disease.
\end{abstract}

\section{Introduction}

IgA nephropathy (IgAN) is the most common form of chronic glomerulonephritis for individuals of European and Asian descent $[1,2]$. The level of proteinuria at diagnosis of IgAN has been associated with the primary endpoint of outcome (i.e., progression to chronic dialysis or transplantation) in adults [3-7] and children [8-11].

Data from clinical and basic research in IgAN has led to the hypothesis that four hits are responsible for clinical expression of IgAN [12]. The first hit is the presence of aberrantly glycosylated $O$-linked glycans on the heavy-chain hinge region of circulatory IgA1 that terminate in $\mathrm{N}$-acetylgalactosamine (GalNAc) rather than galactose [13]. Elevated serum levels of this galactose-deficient IgA1 (Gd-IgA1) were found in $76 \%$ of 153 Caucasian adults with IgAN in the United States [14]. IgAN patients in Japan and China also had elevated serum Gd-IgA1 levels $[15,16]$, as did AfricanAmerican patients in the southeastern United States [17]. In addition, elevated serum Gd-IgA1 levels were found in 77\% 
of 22 African-American and Caucasian children with IgAN [18].

The second hit is the induction of circulating IgG or IgA antibodies specific for Gd-IgA1 [19], and the third hit is the resultant formation of nephritogenic immune complexes and their deposition in the glomerular mesangium. The final hit is the induction by these immune complexes of a local proliferative and inflammatory response of the mesangial cells [20-22]. Logically, the events related to the fourth hit would be directly or indirectly responsible for the induction of proteinuria in IgAN. In a recent study, the percentage of serum Gd-IgAl relative to serum total IgAl was found to correlate with proteinuria at time of sampling and over the follow-up interval in 62 pediatric and adult patients [23]. Those data differed from the findings at the time of sampling in our initial report with adult patients [14]. The aim of the present study was to determine whether the serum level of Gd-IgA1 associates with proteinuria in a well-characterized cohort of pediatric patients with IgAN.

\section{Patients and Methods}

2.1. Study Population. The subjects had been entered into earlier studies approved by the Institutional Review Boards of the University of Tennessee Health Science Center and the University of Alabama at Birmingham. The diagnosis of IgAN was established by renal biopsy showing IgA as the dominant or codominant immunoglobulin in a typical mesangial distribution, in the absence of clinical and laboratory evidence for systemic disease [24]. All subjects were younger than 18 years of age at the time of diagnostic biopsy. This study did not enroll children who had received a kidney transplant or who were on dialysis. Data for initial serum Gd-IgA1 level were previously reported for 22 of the patients included in the present report [17]. Of the 40 patients in this study, 31 were diagnosed and followed up by the pediatric nephrology group at the Le Bonheur Children's Hospital (LBCH) in Memphis, TN (LBCH cohort), five were diagnosed at other centers and seen in consultation at $\mathrm{LBCH}$, two were diagnosed and followed in Lexington, KY, and two in Birmingham, AL.

Serum samples were available from 97 healthy controls younger than 18 years. The control group included 29 African-American males, 21 African-American females, 28 Caucasian males, and 19 Caucasian females.

2.2. Laboratory Measures and Data Collection. Blood samples were collected from patients on one or more occasions for determination of serum total IgA, Gd-IgA1, and creatinine concentration. Urinary protein and creatinine concentrations were measured in the clinical laboratory from a random spot urine sample, and a urinary protein/creatinine ratio (UPCR) (g/g) was calculated. Estimated GFR was calculated with the new Schwartz formula [25]. Systolic and diastolic blood pressure percentiles based upon age, gender, and height percentile were determined by the tables from the Fourth Report on the Diagnosis, Evaluation, and Treatment of High Blood Pressure in Children and Adolescents [26].
The blood pressure used for this calculation was the average of available measurements within two months of biopsy, if more than one was recorded. BMI percentile was determined using the QuesGen Systems, Inc. web-based calculator that used National Health and Nutrition Examination Survey data as the source for calculations (http:// www.quesgen.com/BMIPedsCalc.php).

Time-average (TA) proteinuria was determined according to the description of Reich et al. [7], except that UPCR was used instead of results of timed urine collections. The UPCR was determined for each six-month interval after biopsy; if there were two or more values for an interval, the mean of the values was used. The TA-UPCR was derived by averaging these UPCRs from each six-month interval of follow-up time.

Serum total IgA and Gd-IgA1 levels were determined by ELISA, as described previously [14]. The Gd-IgA1 ELISA used biotinylated lectin from Helix aspersa (Sigma-Aldrich, St. Louis, MO, USA) that binds specifically to terminal GalNAc. Two galactose-deficient IgA1 myeloma proteins, $\mathrm{McE}$ and Ale, were used as standards in the Gd-IgA1 assays. Results for levels of Gd-IgA1 were expressed as U/mL serum, with $1 \mathrm{U}$ (unit) corresponding to $1 \mu \mathrm{g}$ of Gd-IgA1 myeloma standard protein. During the course of the study, the standard in the assay was changed from McE to Ale; the latter IgA1 myeloma protein has a slightly higher content of terminal GalNAc. The McE standard had been used exclusively for our initial reports [14, 17]. Subsequent levels determined using the Ale standard were multiplied by a factor of 2.5 to be compared to those determined in assays using the McE protein as standard.

2.3. Statistical Analyses. The Mann-Whitney $U$ test was used to determine differences between patient and control groups for serum levels of Gd-IgA1 and percent Gd-IgA1/IgA. Spearman's correlation coefficients were used to assess the relationship between study variables. SAS 9.1 (SAS Institute, Cary, NC, USA) was used for descriptive statistics and calculation of correlation coefficients.

\section{Results}

Incident cases are defined as those having a serum Gd-IgA1 level first measured within 3 months after the diagnostic biopsy. Prevalent cases had their first Gd-IgA1 measurement after longer intervals. Clinical and demographic data are shown in Table 1 for the incident cases and in Table 2 for the prevalent cases.

The LBCH cohort differed from the other cases because of higher percentages of African-Americans and subjects with TA-UPCR determinations Table 3 . The 40 patients included 29 Caucasians and 11 African Americans; 26 were male. For the IgAN group, the mean age $\pm \mathrm{SD}$ at diagnosis was $11.7 \pm 3.7$ years and $13.2 \pm 3.7$ years at the time the first serum for Gd-IgA1 level was obtained. The mean \pm SD age at time of study was $12.6 \pm 2.9$ years for the healthy control group. 
TABLE 1: Clinical and demographic features of individual subjects (incident cases).

\begin{tabular}{|c|c|c|c|c|c|c|c|c|}
\hline Subject & Race/gender & Presentation & $\begin{array}{l}\text { Age at } \\
\text { biopsy }\end{array}$ & $\begin{array}{c}\text { estGFR } \\
\left(\mathrm{mL} / \mathrm{min} / 1.73 \mathrm{~m}^{2}\right)\end{array}$ & $\begin{array}{l}\text { Urinary protein/ } \\
\text { creatinine ratio }\end{array}$ & $\begin{array}{c}\text { BMI } \\
\text { percentile }\end{array}$ & $\begin{array}{l}\text { SBP/DBP } \\
\text { percentile }\end{array}$ & $\begin{array}{l}\text { Serum Gd-IgA1 } \\
\text { level (units } / \mathrm{mL} \text { ) }\end{array}$ \\
\hline $\mathrm{A} 1$ & $\mathrm{C} / \mathrm{M}$ & $\begin{array}{l}\text { Microhematuria, } \\
\text { proteinuria }\end{array}$ & 17.6 & 59 & 1.17 & 98 & $95-99 /<50$ & 262 \\
\hline M2 & $\mathrm{C} / \mathrm{M}$ & Isolated proteinuria & 13.8 & 78 & 1.24 & 26 & 95-99/50-90 & 889 \\
\hline M15 & $\mathrm{C} / \mathrm{F}$ & Gross hematuria & 11.2 & 80 & 1.31 & $<1$ & $<50 / 50-90$ & 1076 \\
\hline M16 & $\mathrm{C} / \mathrm{F}$ & Gross hematuria & 8.7 & 75 & 1.00 & 57 & $50-90 /<50$ & 1073 \\
\hline M17 & $\mathrm{C} / \mathrm{M}$ & Gross hematuria & 13.4 & 108 & 3.10 & 11 & 50-90/50-90 & 1534 \\
\hline M18 & $\mathrm{C} / \mathrm{F}$ & Recurrent gross hematuria & 12.5 & 107 & 2.96 & 17 & $>99 /<50$ & 1155 \\
\hline M19 & $\mathrm{AA} / \mathrm{F}$ & $\begin{array}{l}\text { Gross hematuria, } \\
\text { rapidly progressive } \\
\text { glomerulonephritis }\end{array}$ & 15.9 & 49 & 2.97 & 52 & $<50,<50$ & 3401 \\
\hline M21 & $\mathrm{AA} / \mathrm{M}$ & Isolated proteinuria & 5.1 & 94 & 3.58 & 96 & $<50,50-90$ & 747 \\
\hline M22 & $\mathrm{C} / \mathrm{M}$ & $\begin{array}{l}\text { Gross hematuria, } \\
\text { acute kidney injury }\end{array}$ & 8.6 & 75 & 1.33 & 49 & $95-99 / 50-90$ & 803 \\
\hline M26 & $\mathrm{AA} / \mathrm{M}$ & Gross hematuria & 8.8 & 120 & 3.70 & 30 & $90-95 / 50-90$ & 470 \\
\hline M28 & $\mathrm{C} / \mathrm{F}$ & $\begin{array}{l}\text { Gross hematuria, } \\
\text { proteinuria }\end{array}$ & 16.7 & 63 & 1.36 & 40 & $90-95 / 50-90$ & 1110 \\
\hline M29 & $\mathrm{C} / \mathrm{M}$ & Gross hematuria & 12.8 & 96 & 0.95 & 41 & $>99 / 95-99$ & 659 \\
\hline M30 & $\mathrm{C} / \mathrm{M}$ & $\begin{array}{l}\text { Gross hematuria, } \\
\text { acute kidney injury }\end{array}$ & 15.0 & 61 & 2.89 & 63 & $90-95 / 50-90$ & 364 \\
\hline M31 & $\mathrm{C} / \mathrm{M}$ & Gross hematuria & 16.2 & 84 & 0.25 & 89 & 50-90/50-90 & 2513 \\
\hline $\mathrm{T} 2$ & $\mathrm{C} / \mathrm{M}$ & $\begin{array}{l}\text { Microhematuria, proteinuria, } \\
\text { Chronic kidney } \\
\text { disease stage } 3\end{array}$ & 17.8 & 40 & 1.27 & 44 & $95-99 / 50-90$ & 796 \\
\hline
\end{tabular}

AA: African-American; BMI: body mass index; C: Caucasian; estGFR, estimated glomerular filtration rate; DBP: diastolic blood pressure; SBP: systolic blood pressure; microhematuria, $>5 \mathrm{RBC} /$ high powered field.

Measurements of serum Gd-IgA1 and UPCR on the same date were available on at least one occasion for 40 patients; 13 patients had from two to four paired samples over the course of observation. A total of 62 paired samples for serum GdIgA1 and UPCR were available for analysis.

The initial serum Gd-IgA1 levels for the patient and control groups are shown in Figure 1(a). The patient group levels were significantly higher than those of the control group $(P<0.0001)$. The median serum Gd-IgA1 level for 97 healthy controls under age 18 years was $260 \mathrm{U} / \mathrm{mL}$ (interquartile range (IQR) $183-334 \mathrm{U} / \mathrm{mL}$ ). Based upon these controls, the 90th and 95th percentiles were $482 \mathrm{U} / \mathrm{mL}$ and $645 \mathrm{U} / \mathrm{mL}$, respectively. For patients, median serum GdIgA1 level was $688 \mathrm{U} / \mathrm{mL}$ (IQR $517-1238 \mathrm{U} / \mathrm{mL}$ ) and the median total serum IgA level was 2499 U/mL (IQR 1930$4072 \mathrm{U} / \mathrm{mL})$.

The initial medians for percent Gd-IgA1/total serum IgA for the patient and control groups are shown in Figure 1(b). The patient group levels were significantly higher than those of the control group $(P<0.0001)$. The median percent GdIgA1/total serum IgA level for 97 healthy controls under age 18 years was $17 \%$, with an IQR of $10 \%$ to $22 \%$. Based upon these controls, the 90th and 95th percentiles were $32 \%$ and $34 \%$, respectively. For patients, initial median percent GdIgA1/total serum IgA was 32\% (IQR 26\%-48\%). The median UPCR was $0.74 \mathrm{~g} / \mathrm{g}$ (IQR $0.23-1.68 \mathrm{~g} / \mathrm{g}$ ).
Spearman's correlation coefficients were also calculated for serum Gd-IgAl, percent Gd-IgA1, age at biopsy, and length of follow-up versus initial UPCR and TA-UPCR. For patients having two or more measurements for serum GdIgA1 and percent Gd-IgA1, the mean of these measurements was used for the calculation of correlation coefficients versus TA-UPCR. Again, all correlations were determined to be statistically insignificant and are as follows: serum Gd-IgA1 versus UPCR $(r=0.05, P=0.72$; Figure 2(a)), percent serum Gd-IgA1 versus UPCR $(r=-0.11, P=0.38$; Figure 2(b)), serum Gd-IgAl versus TA-UPCR $(r=0.06$, $P=0.75$; Figure 3(a)), percent serum Gd-IgA1 versus TAUPCR $(r=0.04, P=0.87$; Figure 3(b)), age at time of biopsy versus TA-UPCR $(r=0.18, P=0.32)$, and length of followup versus TA-UPCR $(r=0.10, P=0.60)$. Of the 3 patients who progressed to ESRD, all had TA-UPCR above 1.0 and two had serum Gd-IgA1 levels above the 95th percentile for healthy children.

UPCR and serum Gd-IgA1 levels were plotted against age for the subject with the longest period of serial serum GdIgA1 sampling (Figure 4). This clinical course is of interest in that the blood sample for measurement of the first level was obtained during an episode of gross hematuria at time of diagnosis and the last three blood samples were collected during clinical remission (urinalysis, UPCR and serum creatinine concentration all normal). 
TABLE 2: Clinical and demographic features of individual subjects (prevalent cases).

\begin{tabular}{|c|c|c|c|c|c|c|c|c|}
\hline Subject & Race/gender & Presentation & $\begin{array}{l}\text { Age at } \\
\text { biopsy }\end{array}$ & $\begin{array}{c}\text { estGFR } \\
\left(\mathrm{mL} / \mathrm{min} / 1.73 \mathrm{~m}^{2}\right)\end{array}$ & $\begin{array}{l}\text { Urinary protein/ } \\
\text { creatinine ratio }\end{array}$ & $\begin{array}{c}\text { BMI } \\
\text { percentile }\end{array}$ & $\begin{array}{l}\text { SBP/DBP } \\
\text { percentile }\end{array}$ & $\begin{array}{l}\text { Serum Gd-IgA1 } \\
\text { level (units/mL) }\end{array}$ \\
\hline $\mathrm{A} 2$ & $\mathrm{AA} / \mathrm{F}$ & $\begin{array}{l}\text { Gross hematuria, } \\
\text { proteinuria }\end{array}$ & 15.9 & 98 & 1.13 & 99 & 95-99/95-99 & 1320 \\
\hline $\mathrm{A} 3$ & $\mathrm{C} / \mathrm{F}$ & $\begin{array}{l}\text { Gross hematuria, } \\
\text { nephrotic syndrome }\end{array}$ & 6.8 & 82 & 5.00 & 54 & & 753 \\
\hline K1 & $\mathrm{C} / \mathrm{M}$ & Gross hematuria & 11.2 & 87 & 1.40 & 99 & $50-90 / 50-90$ & 704 \\
\hline K2 & $\mathrm{C} / \mathrm{M}$ & $\begin{array}{l}\text { Microhematuria, } \\
\text { proteinuria }\end{array}$ & 13.2 & 138 & 0.41 & 99 & $>99 / 50-90$ & 919 \\
\hline M1 & $\mathrm{AA} / \mathrm{M}$ & $\begin{array}{l}\text { Microhematuria, } \\
\text { proteinuria }\end{array}$ & 9.3 & 108 & $300 \mathrm{mg} / \mathrm{dL}^{*}$ & 97 & 95-99/50-90 & 1328 \\
\hline M3 & $\mathrm{C} / \mathrm{M}$ & $\begin{array}{l}\text { Isolated proteinuria, } \\
\text { chronic kidney disease } \\
\text { stage } 3\end{array}$ & 13.0 & 50 & 4.12 & 95 & 95-99/50-90 & 594 \\
\hline M4 & $\mathrm{C} / \mathrm{M}$ & $\begin{array}{l}\text { Recurrent gross hematuria, } \\
\text { acute kidney injury }\end{array}$ & 14.5 & 79 & 0.72 & 93 & $90-95 / 50-90$ & 1867 \\
\hline M5 & $\mathrm{C} / \mathrm{F}$ & Gross hematuria & 11.6 & 79 & 3.61 & 61 & 95-99/50-90 & 363 \\
\hline M6 & $\mathrm{C} / \mathrm{M}$ & Gross hematuria & 11.6 & 98 & $255 \mathrm{mg}^{* *}$ & 74 & 90-95/95-99 & 2177 \\
\hline M7 & $\mathrm{AA} / \mathrm{F}$ & $\begin{array}{l}\text { Gross hematuria, } \\
\text { nephrotic syndrome, } \\
\text { acute kidney injury }\end{array}$ & 10.4 & 70 & 3.29 & 33 & 50-90/50-90 & 315 \\
\hline M8 & $\mathrm{C} / \mathrm{M}$ & Gross hematuria & 17.4 & 67 & 0.44 & 94 & 90-95/50-90 & 1054 \\
\hline M9 & $\mathrm{C} / \mathrm{M}$ & Recurrent gross hematuria & 16.5 & 100 & 0.41 & 76 & 90-95/50-90 & 861 \\
\hline M10 & $\mathrm{AA} / \mathrm{M}$ & Recurrent gross hematuria & 7.0 & 102 & 0.64 & 90 & 95-99/50-90 & 563 \\
\hline M11 & $\mathrm{AA} / \mathrm{F}$ & Gross hematuria & 5.5 & 95 & $30 \mathrm{mg} / \mathrm{dL}^{*}$ & 93 & $50-90 /<50$ & 882 \\
\hline M12 & $\mathrm{C} / \mathrm{M}$ & Gross hematuria & 8.5 & 87 & 0.04 & 15 & 50-90/50-90 & 612 \\
\hline
\end{tabular}

AA: African-American; BMI: body mass index; C: Caucasian; estGFR: estimated glomerular filtration rate; DBP: diastolic blood pressure; SBP: systolic blood pressure.

*Amount of protein by urinary dipstick;

** Amount of protein in 24 hours.

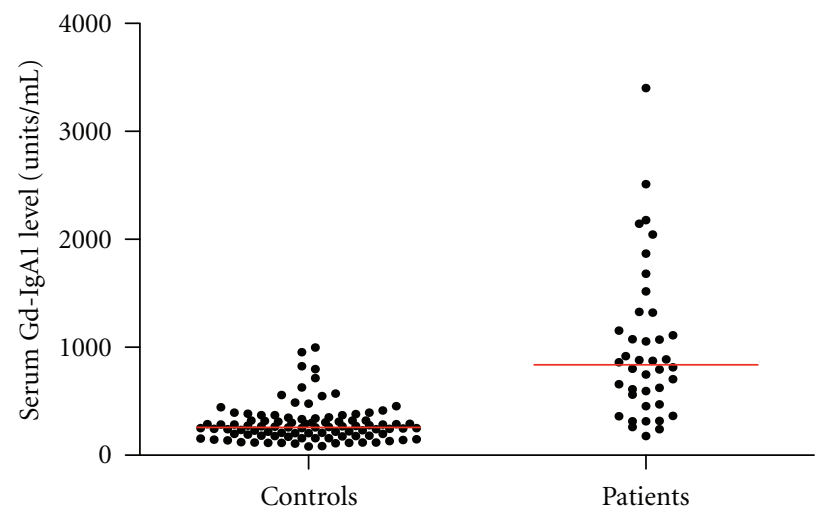

(a)

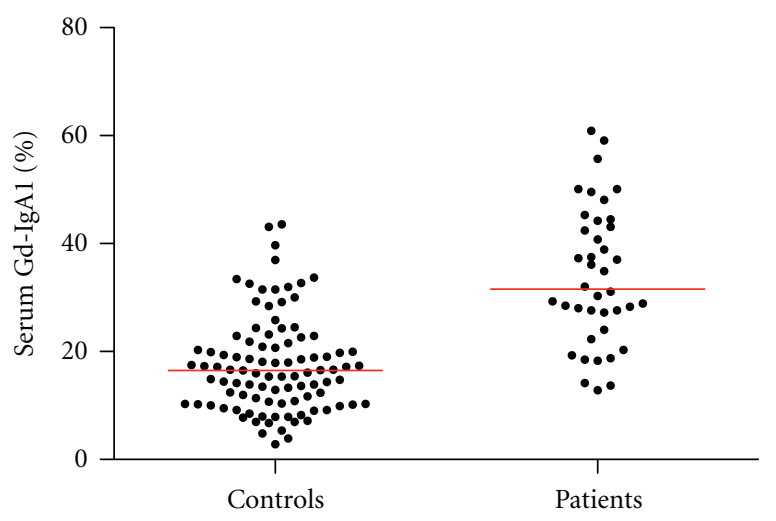

(b)

FIGURE 1: Serum levels of Gd-IgA1 plotted for the initial sample for 40 pediatric patients and 97 healthy pediatric controls. (a) Represented as units/mL serum. Median is represented for each group. The serum level was significantly higher for the patient group $(P<0.0001)$. (b) Represented as percentage of total IgA. Median is represented for each group by the red bar. The serum level was significantly higher for the patient group $(P<0.0001)$. 


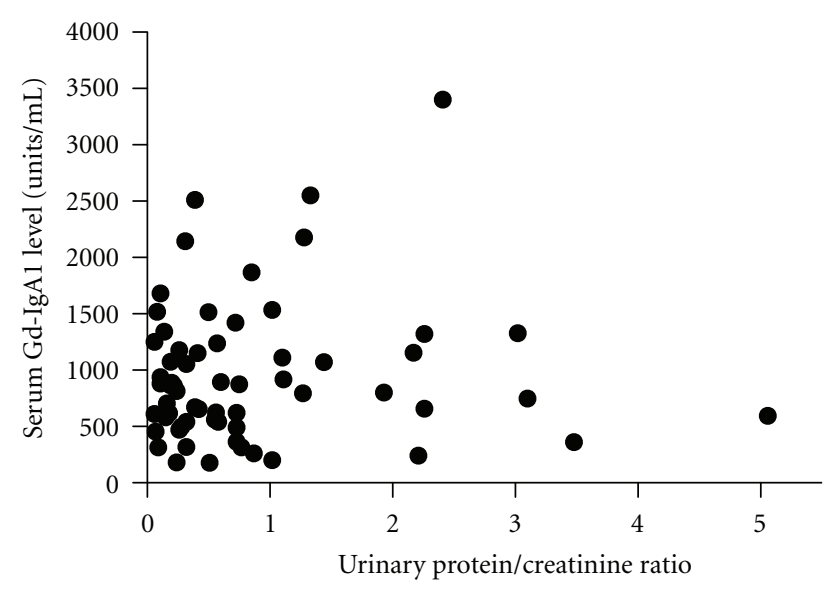

(a)

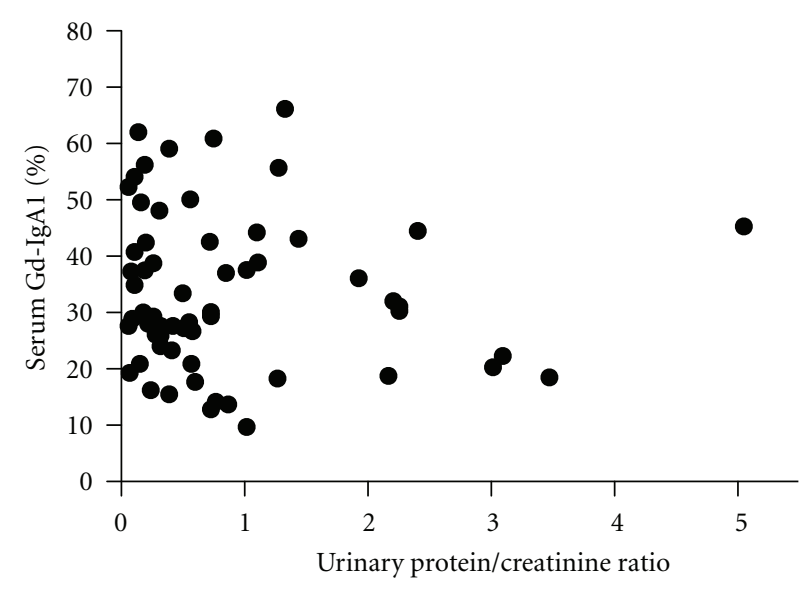

(b)

FIGURE 2: Random urinary protein/creatinine ratios. (a) Plotted against serum Gd-IgA1 levels. Spearman's rank correlation is $r=0.05$, $P=0.72$. (b) Plotted against percent Gd-IgA1 levels. Spearman's rank correlation is $r=-0.11, P=0.38$.

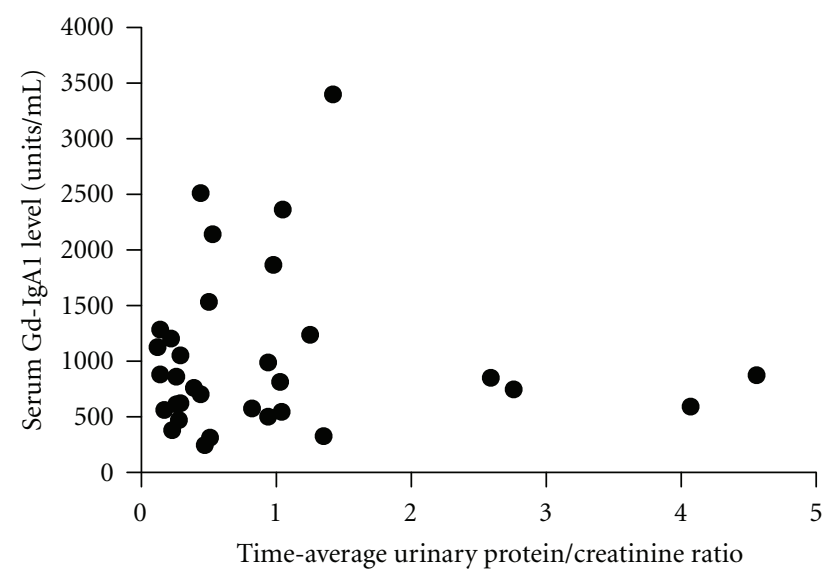

(a)

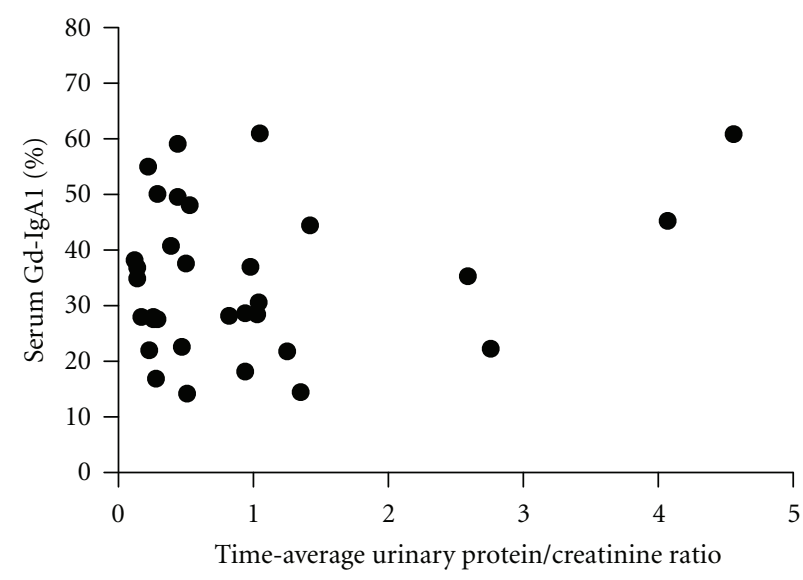

(b)

FIGURE 3: Time-average urinary protein/creatinine ratios. (a) Plotted against average serum Gd-IgA1 levels. Spearman's rank correlation is $r=0.06, P=0.75$. (b) Plotted against serum percent Gd-IgA1 levels. Spearman's rank correlation is $r=0.04, P=0.87$.

\section{Discussion}

Remission of proteinuria is an important predictor of renal survival. Analysis of 542 adult patients with IgAN in the Toronto Glomerulonephritis Registry showed that when treatment achieved a mean urinary protein excretion $<1 \mathrm{~g} /$ day over the follow-up interval, the decline in glomerular filtration rate was markedly slower than that for the entire cohort [7]. Thus, magnitude of proteinuria is a useful surrogate marker of outcome in IgAN patients detected early in the course of disease when renal clearance function is normal.

Serum Gd-IgA1 level can be expressed as an absolute level or as a percentage of total serum IgA. In our earlier cohort of 153 adults with IgAN, the absolute serum level was a better diagnostic marker than percent Gd-IgA1, but neither GdIgA1 $(r=-0.128, P=0.211)$ [14] nor percent Gd-IgA1 $(r=-0.022, P=0.788)$ (previously unpublished data) correlated significantly with UPCR. In that study, only 24 subjects were sampled within 8 weeks of biopsy for measurement of the serum Gd-IgA1 level [14]. However, the median serum Gd-IgA1 level for those 24 subjects was similar to the median for 26 subjects who had levels measured at the last follow-up when the urinalysis and UPCR were normal.

In a Japanese cohort, however, there was no clinically significant difference in magnitude of proteinuria when subjects over the age of 16 years were stratified by serum GdIgA1 level above versus below the 90th percentile for healthy controls [15]. The urine protein excretion for the 20 subjects with serum Gd-IgA1 levels above the 90th percentile was $1.0 \mathrm{~g} /$ day versus $1.1 \mathrm{~g} /$ day for the 21 subjects with lower serum Gd-IgA1 levels. About 95\% of the serum samples used for that study were obtained at the time of biopsy.

In a study by Camilla et al. [23], their cohort included adults and children with IgAN and a correlation between percent Gd-IgA1/IgA and contemporaneous UPCR was 
TABLE 3: Clinical and demographic features of cohorts.

\begin{tabular}{lcc}
\hline & LBCH cohort & Other Cases \\
& $n=31$ & $n=9$ \\
\hline Incident cases & 13 & 2 \\
Prevalent cases & 18 & 7 \\
Male & 21 & 5 \\
Female & 10 & 4 \\
Caucasian & 21 & 8 \\
African-American & 10 & 1 \\
Age at biopsy, yrs & $11.5 \pm 4.7$ & $12.4 \pm 4.9$ \\
Follow-up after biopsy all & $4.2 \pm 2.4$ & $1.9 \pm 2.0$ \\
$\quad$ patients, yrs, mean \pm SD & 3 & 0 \\
CKD5 at last follow-up & 29 & 3 \\
TA-UPCR data, patients & & \\
Follow-up after biopsy for & $4.2 \pm 2.4$ & $3.1 \pm 2.1$ \\
$\quad$ TA-UPCR patients, yr, mean \pm SD & & \\
$\quad$ TA-UPCR $\geq 1.0$ & 9 & 0 \\
$\quad$ TA-UPCR $\geq 0.5,<1.0$ & 7 & 2 \\
$\quad$ TA-UPCR $<0.5$ & 13 &
\end{tabular}

CKD5: chronic kidney disease stage 5; LBCH: Le Bonheur Children's Hospital; SD: standard deviation; TA-UPCR: time-average urinary protein/creatinine ratio; yrs: years.

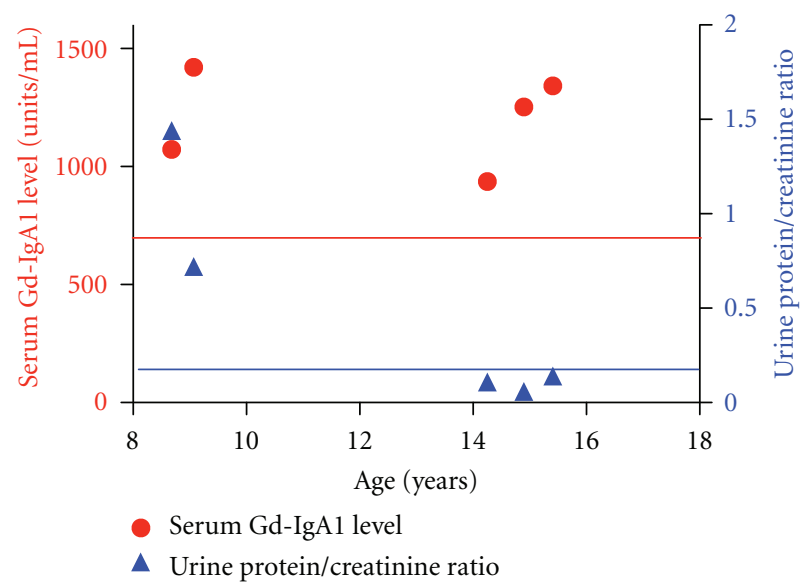

Figure 4: Serum Gd-IgA1 levels (red circles) and concomitant urinary protein/creatinine ratios are plotted for the patient having the most serum Gd-IgA1 determinations. The red line represents the 95th percentile for serum Gd-IgA level in healthy pediatric controls, and the blue line represents the upper limit of normal for urinary protein/creatinine ratio of 0.2 . This time course is of interest in that the initial value was at presentation with gross hematuria and the last three values were obtained during clinical remission (normal urinalysis and estimated GFR).

found to be marginally significant $(r=0.25, P=0.03$ ). The correlation improved when TA-UPCR for each patient was correlated against a single serum Gd-IgA1 level $(r=0.29$, $P=0.007)$. Our failure to confirm this finding in a pediatric cohort is not easily explained. A possible basis is a difference in severity of disease. Our pediatric cohort had a higher percentage of patients with low TA-proteinuria.

Serum Gd-IgA1 and percent Gd-IgA1 levels are often elevated in first-degree relatives of patients with IgAN [15, $27,28]$. However, virtually all of these affected relatives had no clinical evidence for renal disease prior to or at the time of blood sampling $[15,27,28]$. In addition, careful examination of the values for healthy controls indicates that serum GdIgA1 levels are distributed in a nonparametric manner, such that at least $5 \%$ of the subjects had a level higher than predicted by a normal distribution [14, 15, 23].

Thus, the presence of serum Gd-IgA1 is necessary but not sufficient to precipitate the renal injury in IgAN [12]. In the study of Suzuki et al. [19], levels of IgG specific for Gd-IgAl correlated with UPCR $(P<0.0001)$ and with the levels of IgA-IgG immune complexes normalized to urinary creatinine $(P=0.0082)$ in contemporaneously collected urine samples. This prognostic significance may be due to a requirement for the formation of immune complexes to sustain renal injury in IgAN. The serum Gd-IgA1 level seems to be more valuable as a marker for risk of disease rather than for prognosis [14].

\section{Conclusion}

In a cohort of pediatric patients with IgAN, we failed to confirm a recently described association between the magnitude of proteinuria and percent serum Gd-IgA1/IgA [21]. This finding is similar to that in our initial North American cohort and a Japanese cohort of adults [14, 15]. Thus, the weight of the evidence to date fails to support a relationship between the serum Gd-IgA1 level and severity of proteinuria. This clinical expression of disease in IgAN is likely influenced by other factors or hits, such as levels of circulating antibodies specific for Gd-IgA1, level and/or composition of Gd-IgA1-containing immune complexes, or other factors that influence mesangial inflammation.

\section{Acknowledgments}

Dr. M. C. Hastings was supported by a research career development award from the Clinical and Translational Research Institute of the University of Tennessee Health Science Center and a grant from the Le Bonheur Children's Hospital. This study was also supported by a generous gift to the UTHSC Pediatric Nephrology Research Fund by Don and Anna Waite. Drs. R. J. Wyatt, J. Novak, B. A. Julian, and Z. Moldoveanu were supported by grant no. DK082753 from the National Institute of Diabetes and Digestive and Kidney Diseases (NIDDK). Dr. J. T. Sanders was supported by a fellowship training award from the National Kidney Foundation. The authors also acknowledge other grants from NIDDK supporting their research of IgAN: DK078244, DK080301, DK075868, DK083663, DK082753, and GM098539. The contents of this paper are solely the responsibility of the authors and do not necessarily represent the official view of NCRR, NIDDK, or NIH. 


\section{References}

[1] G. D'Amico, “The commonest glomerulonephritis in the world: IgA nephropathy," Quarterly Journal of Medicine, vol. 64, no. 245, pp. 709-727, 1987.

[2] M. Levy and J. Berger, "Worldwide perspective of IgA nephropathy," American Journal of Kidney Diseases, vol. 12, no. 5, pp. 340-347, 1988.

[3] M. G. Radford Jr., J. V. Donadio Jr., E. J. Bergstralh, and J. P. Grande, "Predicting renal outcome in IgA nephropathy," Journal of the American Society of Nephrology, vol. 8, no. 2, pp. 199207, 1997.

[4] P. Ruggenenti, A. Perna, L. Mosconi, R. Pisoni, and G. Remuzzi, "Urinary protein excretion rate is the best independent predictor of ESRF in non-diabetic proteinuric chronic nephropathies," Kidney International, vol. 53, no. 5, pp. 1209-1216, 1998.

[5] J. V. Donadio, E. J. Bergstralh, J. P. Grande, and D. M. Rademcher, "Proteinuria patterns and their association with subsequent end-stage renal disease in IgA nephropathy," Nephrology, Dialysis and Transplantation, vol. 17, no. 7, pp. 1197 1203, 2002.

[6] C. C. Geddes, V. Rauta, C. Gronhagen-Riska et al., "A tricontinental view of IgA nephropathy," Nephrology, Dialysis and Transplantation, vol. 18, no. 8, pp. 1541-1548, 2003.

[7] H. N. Reich, S. Troyanov, J. W. Scholey, and D. C. Cattran, "Remission of proteinuria improves prognosis in IgA nephropathy," Journal of the American Society of Nephrology, vol. 18, no. 12, pp. 3177-3183, 2007.

[8] R. J. Hogg, F. G. Silva, R. J. Wyatt, J. S. Reisch, J. C. Argyle, and D. A. Savino, "Prognostic indicators in children with IgA nephropathy-report of the Southwest Pediatric Nephrology Study Group," Pediatric Nephrology, vol. 8, no. 1, pp. 15-20, 1994.

[9] R. J. Wyatt, S. B. Kritchevsky, S. Y. Woodford et al., "IgA nephropathy: long-term prognosis for pediatric patients," Journal of Pediatrics, vol. 127, no. 6, pp. 913-919, 1995.

[10] G. Ariceta, N. Gallego, Y. Lopez-Fernandez et al., "Pronóstico en la vida adulta de la nefropatía IgA diagnosticada en la edad pediátrica," Medicina Clinica, vol. 116, no. 10, pp. 361-364, 2001.

[11] N. Yata, K. Nakanishi, Y. Shima et al., "Improved renal survival in Japanese children with IgA nephropathy," Pediatric Nephrology, vol. 23, no. 6, pp. 905-912, 2008.

[12] H. Suzuki, K. Kiryluk, J. Novak et al., "The pathophysiology of IgA nephropathy," Journal of the American Society of Nephro$\log y$, vol. 22, no. 10, pp. 1795-1803, 2011.

[13] J. Mestecky, M. Tomana, Z. Moldoveanu et al., "Role of aberrant glycosylation of IgA1 molecules in the pathogenesis of iga nephropathy," Kidney and Blood Pressure Research, vol. 31, no. 1, pp. 29-37, 2008.

[14] Z. Moldoveanu, R. J. Wyatt, J. Y. Lee et al., "Patients with IgA nephropathy have increased serum galactose-deficient IgA1 levels," Kidney International, vol. 71, no. 11, pp. 1148-1154, 2007.

[15] S. Shimozato, Y. Hiki, H. Odani, K. Takahashi, K. Yamamoto, and S. Sugiyama, "Serum under-galactosylated IgA1 is increased in Japanese patients with IgA nephropathy," Nephrology, Dialysis and Transplantation, vol. 23, no. 6, pp. 1931-1939, 2008.

[16] X. Lin, J. Ding, L. Zhu et al., "Aberrant galactosylation of IgA1 is involved in the genetic susceptibility of Chinese patients with IgA nephropathy," Nephrology, Dialysis and Transplantation, vol. 24, no. 11, pp. 3372-3375, 2009.
[17] K. K. Lau, R. J. Wyatt, Z. Moldoveanu et al., "Serum levels of galactose-deficient IgA in children with IgA nephropathy and Henoch-Schönlein purpura," Pediatric Nephrology, vol. 22, no. 12, pp. 2067-2072, 2007.

[18] M. C. Hastings, Z. Moldoveanu, B. A. Julian et al., "Galactosedeficient IgA1 in African Americans with IgA nephropathy: serum levels and heritability," Clinical Journal of the American Society of Nephrology, vol. 5, no. 11, pp. 2069-2074, 2010.

[19] H. Suzuki, R. Fan, Z. Zhang et al., "Aberrantly glycosylated $\operatorname{IgA} 1$ in IgA nephropathy patients is recognized by IgG antibodies with restricted heterogeneity," Journal of Clinical Investigation, vol. 119, no. 6, pp. 1668-1677, 2009.

[20] A. Amore, P. Cirina, G. Conti, P. Brusa, L. Peruzzi, and R. Coppo, "Glycosylation of circulating IgA in patients with IgA nephropathy modulates proliferation and apoptosis of mesangial cells," Journal of the American Society of Nephrology, vol. 12, no. 9, pp. 1862-1871, 2001.

[21] J. Novak, M. Tomana, K. Matousovic et al., "IgA1-containing immune complexes in IgA nephropathy differentially affect proliferation of mesangial cells," Kidney International, vol. 67, no. 2, pp. 504-513, 2005.

[22] J. Novak, L. R. Kafkova, H. Suzuki et al., "IgA1 immune complexes from pediatric patients with IgA nephropathy activate cultured human mesangial cells," Nephrology, Dialysis and Transplantation, vol. 26, no. 11, pp. 3451-3457, 2011.

[23] R. Camilla, H. Suzuki, V. Dapra et al., "Oxidative stress and galactose-deficient IgA1 as markers of progression in IgA Nephropathy," Clinical Journal of the American Society of Nephrology, vol. 6, no. 8, pp. 1903-1911, 2011.

[24] R. J. Wyatt, B. A. Julian, and D. B. Bhathena, "IgA nephropathy: presentation, clinical course, and prognosis in children and adults," American Journal of Kidney Diseases, vol. 4, no. 2, pp. 192-200, 1984.

[25] G. J. Schwartz, A. Muñoz, M. F. Schneider et al., "New equations to estimate GFR in children with CKD," Journal of the American Society of Nephrology, vol. 20, no. 3, pp. 629-637, 2009.

[26] Fourth Report on the Diagnosis, Evaluation, and Treatment of High Blood Pressure in Children and Adolescents, http:// www.nhlbi.nih.gov/health/prof/heart/hbp/hbp_ped.pdf.

[27] A. G. Gharavi, Z. Moldoveanu, R. J. Wyatt et al., "Aberrant IgA1 glycosylation is inherited in familial and sporadic IgA nephropathy," Journal of the American Society of Nephrology, vol. 19, no. 5, pp. 1008-1014, 2008.

[28] K. Kiryluk, Z. Moldoveanu, J. T. Sanders et al., "Aberrant glycosylation of IgA1 is inherited in both pediatric IgA nephropathy and Henoch-Schönlein purpura nephritis," Kidney International, vol. 80, no. 1, pp. 79-87, 2011. 


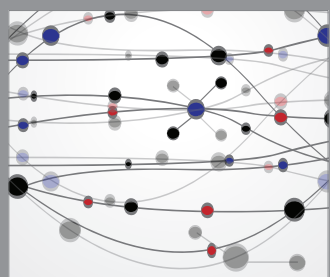

The Scientific World Journal
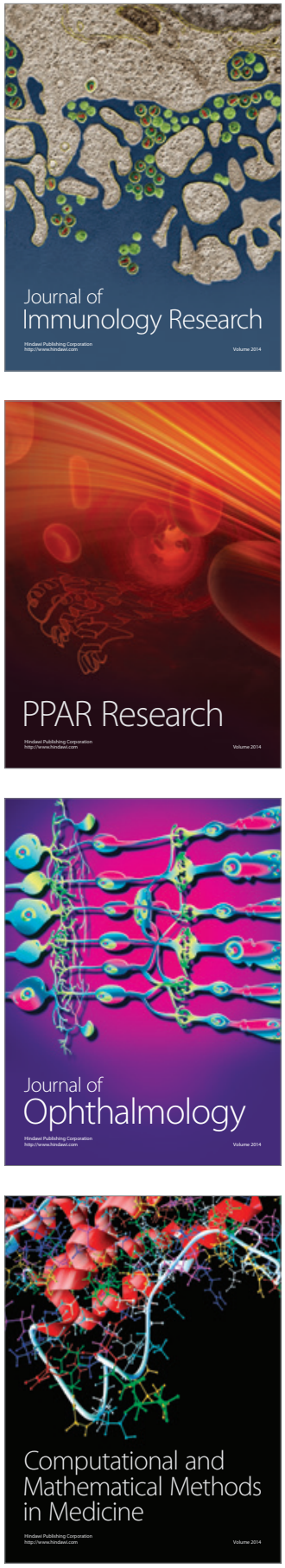

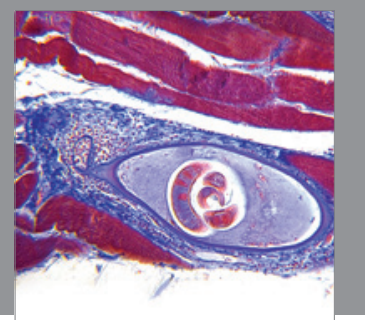

Gastroenterology

Research and Practice
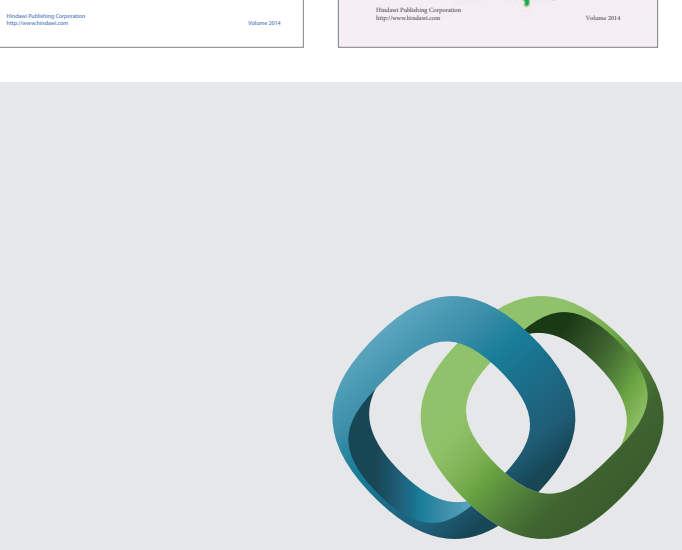

\section{Hindawi}

Submit your manuscripts at

http://www.hindawi.com
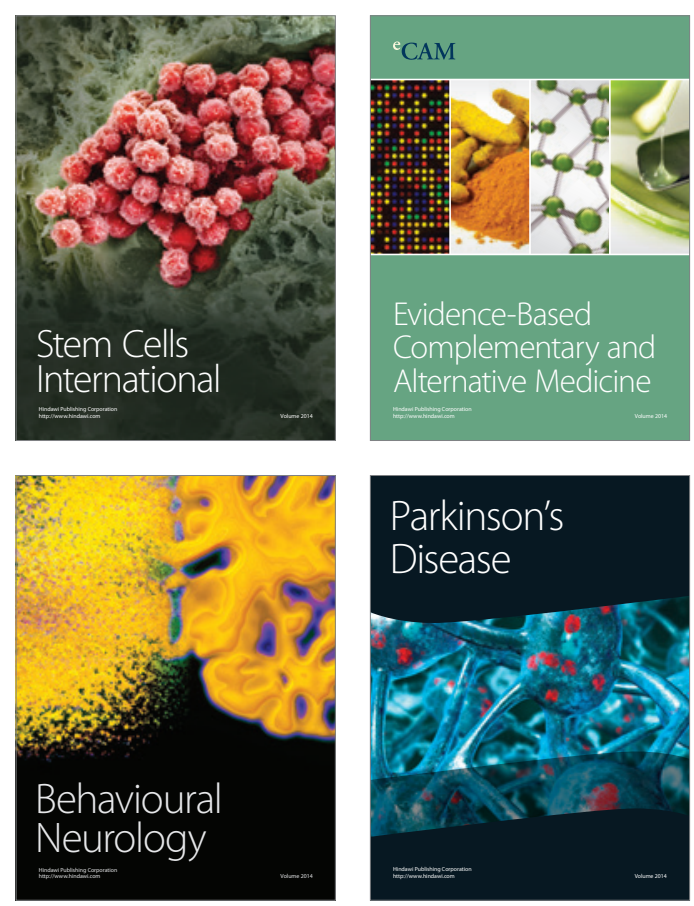



Journal of
Diabetes Research

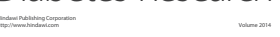

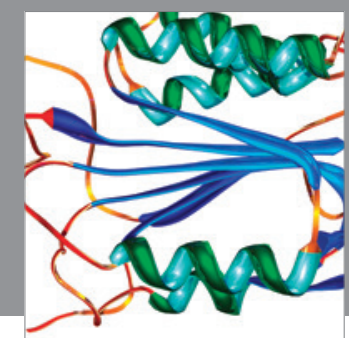

Disease Markers
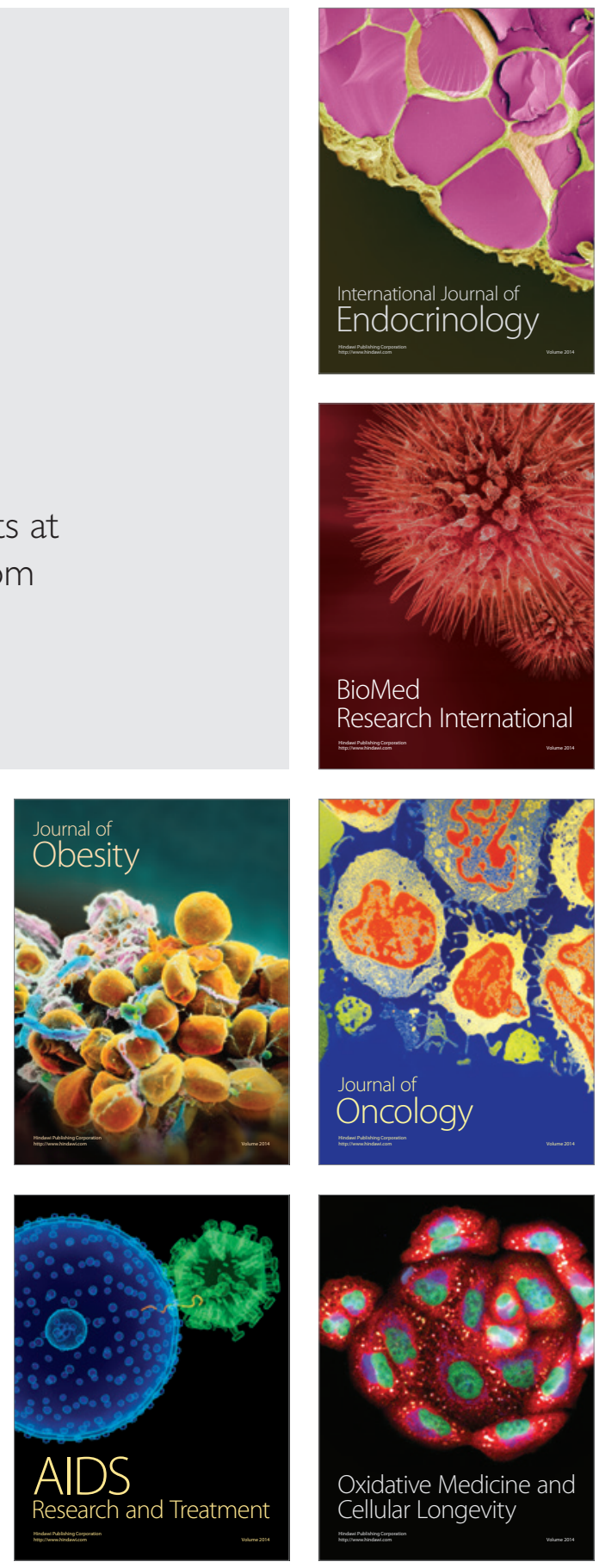